www.jmscr.igmpublication.org Impact Factor (SJIF): 6.379

Index Copernicus Value: 71.58

ISSN (e)-2347-176x ISSN (p) 2455-0450

crossrefDOI: https://dx.doi.org/10.18535/jmscr/v6i6.78

Journal Of Medical Science And Clinical Research

IGM Publication

An Official Publication of IGM Publication

Original Article

\title{
Evaluation of Male Infertility by Testicular FNAC (Fine Needle Aspiration Cytology)
}

\author{
Dr Sanjeev Kamal ${ }^{1}$, Dr Manoj Kumar², Dr Raghvendra Kumar ${ }^{3}$, Dr Mahesh Prasad ${ }^{4}$, \\ Dr Satyendu Sagar ${ }^{5}$ \\ ${ }^{1}$ Tutor, Department of pathology, Sri Krishna Medical College, Muzaffarpur \\ ${ }^{2}$ Associate Professor \& H.O.D, Department of Pathology, Sri Krishna Medical College, Muzaffarpur \\ ${ }^{3}$ Assistant Professor, Department of Pathology, Sri Krishna Medical College, Muzaffarpur \\ ${ }^{4}$ Associate Professor, Department of Pathology, Sri Krishna Medical College, Muzaffarpur \\ ${ }^{5}$ Assistant Professor, Department of Microbiology, Nalanda Medical College Patna \\ Corresponding Author \\ Dr Sanjeev Kamal \\ Tutor, Department of Pathology, Sri Krishna Medical College, Muzaffarpur, India
}

\begin{abstract}
Objective: Testicular fine needle aspiration cytology (FNAC) is an important investigation in management of male infertility, especially to differentiate between obstructive and non obstructive causes of azoospermia. It is less invasive and associated with no or minimal complications. Nowadays when assisted fertilization techniques are being practiced, fibrosis after biopsy may further hamper in sperm extraction for intra cytoplasmic sperm injection (ICSI). Present study was undertaken to evaluate and detailed analysis of aspiration cytology of Testes, in cases of male infertility and also it is compare with Testicular biopsy.
\end{abstract}

Materials and Methods: A total of 36 patients of male infertility were studied, from which 44 testicular aspiration was done and only 3 cases were subjected to testicular biopsy. Aspiration was done twice in 5 cases and thrice in 1 case.

Result: Out of 36 patients with male infertility, there were 32 cases of primary infertility and 4 cases of secondary infertility. Semen analysis showed oligospermia in 4 cases and 32 cases were Azoospermic. Spermatogenesis was present in 28 cases and absent in 6 cases and inadequate in 2 cases. Then all cases were reviewed according to five subcategories. Histological findings were compared with their cytological categories.

Conclusion: The Cytological diagnosis correlated well with histological diagnosis and helped in management of infertility. FNAC can help in management of surgical and medical causes of infertility and can save unnecessary expensive investigations in cases of sertoli cell only syndrome and atrophic patterns. FNAC in combination with semen analysis and serum follicle stimulating hormone levels are of great help in management of male infertility.

Keywords: Testes, FNAC, Biopsy, Infertility, Aspiration. 


\section{Introduction}

Male factors account for about $40-50 \%$ of male infertility. Diagnostic approach to a case of male infertility includes a detailed clinical history and thorough physical examination supported by various laboratory investigations like sperm analysis, hormonal evaluation, detection of antisperm antibodies, sperm function assays and some invasive tests like testicular biopsy or fine needle aspiration cytology. Fine needle aspiration cytology (FNAC) has become one of the important methods of investigation in cases of azoospermia and oligospermia. Although the technique of testicular FNAC was first attempted by Posner (1905) and Huhner (1913), later on most of the work was done by Orbant (1965) and Persson (1971). The technique of testicular FNAC is more than 30 - 50 years old, but has become popular only in recent few years. The reasons for non popularity would have been quite a few like cytological appearances of germ cells differ from that in histology, fear of complications of the procedure like trauma, hematoma or pain and also some lack of experience on behalf of cytologists Though biopsy provides some useful information regarding spermatogenesis and basement membrane status of the seminiferous tubules, it has its own complications like hematoma, very rarely fibrosis and scarring and sampling only a small volume of tissue etc. Fine needle aspiration on the other hand is less invasive and associated with no or minimal complications and gives a better idea about different stages of spermatogenesis.

The present study was carried out with the aim to present experience of testicular FNAC in cases of infertility from a single tertiary care centre and sees its limitation and clinical usefulness over testicular biopsy.

\section{Materials and Methods}

Present study was carried out in the Department of Pathology, Sri Krishna Medical College, Muzaffarpur, with the help of Department of surgery and Department of obstetrics \& gynecology during the period of October 2017 to May 2018. A total of 44 aspirations were done for these 36 patients. It was done twice for 5 cases and thrice for one case. FNA from both testes was performed with 21or 22 gauge needle and a $10 \mathrm{ml}$ syringe mounted on a syringe holder after giving local anesthesia. Site of puncture was in axis perpendicular to the longitudinal axis of testis in the middle portion opposite to the side of epididymis. Usually one pass was made and unstained slides were screened under microscope for adequacy. A maximum of three passes were made. Complications after the procedure were evidenced in three cases. One had hematoma and two developed prolonged testicular pain for about 10-12 hours after the procedure. Air dried smears were stained with May Grunwald Giemsa (MGG) stain and wet fixed smears were stained with $\mathrm{H} \& \mathrm{E}$ and Papanicolaou. Slides were reviewed by three pathologists. Initially the cases were divided into three cateogories: spermatogenic activity present, spermatogenic activity absent or inadequate. The slides were again reviewed and further divided into five subcategories of normal spermatogenesis, maturation arrest, hypospermatogenesis, sertoli cell only syndrome, atrophy or peritubular sclerosis and inadequate. The categories were defined as follows.

Table 1 Pathological Finding of Smear

\begin{tabular}{|l|l|}
\hline Normal Maturation & Spermatogenic to sertoli cell ratio 1.5: 1 \\
\hline $\begin{array}{l}\text { Hypospermatogenesis } \\
\text { Maturation arrest }\end{array}$ & $\begin{array}{l}\text { Spermatogenic to sertoli cell ratio <1.5: 1 } \\
\text { When maturation upto spermatozoa stage was not seen and } \\
\text { arrest was at one of the earlier stages of development }\end{array}$ \\
\hline Sertoli cell only Syndrome & no spermatogenic cells seen \\
\hline Atrophic / Peritubular Sclerosis & scanty sertoli and leydig cells. \\
\hline Inadequate & failure to demonstrate even scanty sertoli and leydig cells \\
\hline
\end{tabular}




\section{Results}

A total of 36 patients were studied with a total of 44 aspirations. Age range was $18-53$ years. There were 32 cases of primary infertility and 4 cases of secondary infertility. Semen analysis showed oligospermia (sperm count $<20$ million/ml) in 4 cases and remainder 32 were azoospermic. Testicular volume was reduced 4 cases with bilateral reduction in 2 cases. According to the initial three categories, 28 cases were of spermatogenesis present, 6 were of spermatogenesis absent and 2 were inadequate. Then the cases were reviewed according to five subcateogories. Normal spermatogenesis was seen in $22(61.12 \%)$ cases, hypospermatogenesis maturation arrest in $3(8.33 \%)$ cases sertoli cell only syndrome in $5(13.89 \%)$ peritubular atrophy and hyalinization in $3(8.33 \%)$ and inadequate in $3(8.33 \%)$ cases respectively. Histology was available in 3 cases which were also reviewed and the diagnostic categories were compared with their cytological categories.

Table 2 Cytological Finding of Smear $(n=36)$

\begin{tabular}{|l|c|c|}
\hline Cytological Finding & Number of Cases & Percentage \\
\hline Normal spermatogenesis & 22 & 61.12 \\
\hline Hypospermatogenesis & 3 & 8.33 \\
\hline Sertoli cell only syndrome & 5 & 13.89 \\
\hline Peritubular atrophy and hyalinization & 3 & 8.33 \\
\hline Inadequate & 3 & 8.33 \\
\hline
\end{tabular}

Pie Chart Showing Cytological Finding of Smear $(n=36)$

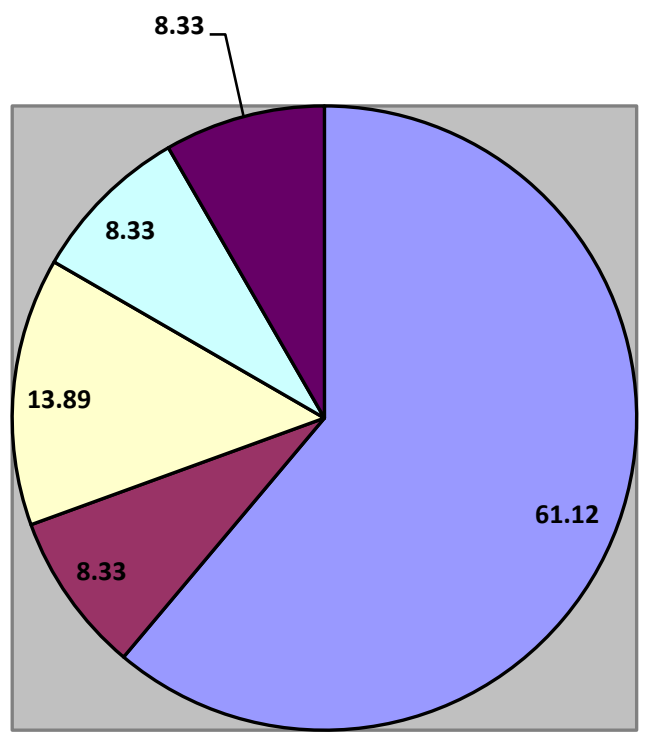

口Normal spermatogenesis

$\square$ Hypospermatogenesis

$\square$ Sertoli cell only syndrome

$\square$ Peritubular atrophy and hyalinization

DInadequate

\section{Discussion}

Fine needle aspiration cytology is a minimally invasive technique which is one of the important investigation in diagnosis and management of infertility. Although hormone level assessment infers a great help in evaluation of testicular function, aspiration cytology is required mostly in cases of obstructive azoospermia.
It helps to differentiate obstructive cases which can be corrected surgically from non obstructive cases. In the current era, micro assisted fertilization techniques are of great help for infertile couples as now a days the only requirement in these techniques is a viable sperm and ovum. Neither quality nor degree of motility is essential. Therefore in cytological smears a 
report of spermatogenesis absent or spermatogenesis present is also adequate. However, if the cases are divided into hypo spermatogenesis and maturation arrest, these patients may be helped to some extent by hormonal therapy. In the present study normal spermatogenesis was much higher than other studies $(61.12 \%)$ cases of hypo spermatogenesis and sertoli cell only were fewer as compared to other studies where as maturation arrest and inadequate category was almost similar.

FNAC serves the purpose with minimum side effects where as biopsy may result in fibrosis which might hamper the process of sperm extraction for intra cytoplasmic sperm injection (ICSI). Thus FNAC as base line investigation in infertility can help in management of surgical as well as medical causes of infertility and also saves unnecessary, more invasive and expensive investigations in cases of sertoli cell only syndrome and atrophic patterns.

FNAC in combination with semen analysis and serum follicle stimulating hormone (FSH) levels can be quite helpful in management of infertility.

\section{Conclusion}

We found that on cytology we could provide reasonably accurate diagnosis, which helped in patient management. An earlier study has emphasized the importance of testicular FNAC over testicular biopsy. This showed that histopathology of testes in cases of infertility being invasive and long procedure, associated with complications has been practically replaced by cytology which is rapid, more sensitive, associated with no or minimal complications and less invasive.

\section{References}

1. Piaton E, Fendler JP, Berger N, Perrin P and Devonec M. Clinical value of Fine Needle Aspiration Cytology and Biopsy in the Evaluation of Male Infertility. Arch Pathol Lab Med1995; 119:722-6.
2. Al-Jitwai SA, Al-Ramahi SA,Hakooz BA. Diagnostic Role of Testicular Fine Needle Biopsy in Male Infertility. Acta Cyto11997; 41(6): 1705-8.3.

3. Persson PS, Ahren C, Obrant KO. Aspiration Biopsy Smears of Testis in Azoospermia: Cytological versus Histological Examination. Scanf Urol Nephro 11971; 5:22-6.

4. Obrant KO, Persson PS. Aspiration Biopsies. Urol Int1965; 20:176-89.

5. Foresta C, Varotto A and Scandellari C. Assessment of Testicular Cytology by Fine Needle Aspiration as a Diagnostic Parameter in the Evaluation of the Azoospermic Patient. Fertil Steri11992; 57(4):858-65.

6. Schenck U and Schill WB. Cytology of Human Seminiferous Epithelium. Acta Cyto11988; 32:689-96.

7. Papic Z, Katona G and Skrabalo Z. The Cytologic Identification and Quantification of Testicular Cell Types: Reproducibility and Relation to Histologic Findings in the Diagnosis of Male Infertility. Acta Cyto11988; 32:697-706.

8. Schenck U and Schill WB. Comparision between Testicular Biopsies and Biopsy Smears in Azoospermia. Androfogia1980; 12:268-75.

9. Abdulla MA, AI-Salim AL, AI-Juwaiser A and Francis I. Fine Needle Aspiration Biopsy of Azoospermic Testes. Could it Replace Histologic Biopsy? Acta Cyto12000; 44(6):967-75.

10. Sabag SG, Glick T and Weiss DB. Fine Needle Aspiration of the Testis and Correlation with Testicular Open Biopsy. Acta Cyto11993; 37(1):67-72.

11. Tesarik J, Mendoza C. Spermatid Injection into Human Oocytes: I. Laboratory Techniques and Special Features of Zygote Development. Hum Reprod1996; 11:7729. 
12. Tesarik J, Rolet F, Brami C,et al. Spermatid Injection into Human Oocytes: II. Clinical Application in the Treatment of Infertility due to Non Obstructive Azoospermia. Hum Reprod1996; 11:780-3.

13. Verma AK, Basu D, Jayaram G. Testicular Cytology in Azoospermia. Diag Cytopathol1992; 9(1):37-42.

14. Batra VV, Kandgawat R, Agarwal A, et al. Correlation of cell counts and indices in testicular FNAC with histology in male infertility. Acta Cyto11999; 43(4):617-23.

15. Srivastava A, Raghavendran M, Jain M, Gupta S, Chaudhary H. Fine-needle aspiration cytology of the testis: can it be a single diagnostic modality in azoospermia? Ural Int 2004; 73(1):23-7. 